water, was then given. This favourable change, however, lasted but three hours. On visiting her at one A.M., she was beginning to sink into an insensible condition; she had not again vomited or purged, neither did the blue colour or corrugation of the skin return; the breathing became hurried, with mucous rhonchus, the pulse gradually failod, and she died at three A.M. on the 26 th.

$I$ am indebted to the kindness of Dr. Marsden, in whose practice the above case occurred, for an opportunity of witnessing the operation of injection and its effects. I must confess that, from previous reading and consideration of this subject, there was much doubt in my own mind as to any benefit that could be derived from such a procedure to a patient in so advanced $a$ : stage of cholera, more especially in the one now reported. The effect, however, was so very marked, and the patient's apparent restoration so perfeet for a limited period, that there seemed to me to be every chance of permanent restoration, had the patient been in a moderate state of previous health, and not so reduced by long-continued disease. It is with a view of drawing attention to the subject of saline injection that the above case is given, in the hope that it may again be thought worthy of trial and investigation, and some useful result obtained, applicable to the relief of such hopeless cases as the majority of those in the collapsed stage of cholera prove to be. The very ably reported case of transfusion, in THE LANCET of the 21st, by Dr. Routh, showed many well-marked signs of improvement, and gave hopes of a more favourable termination; and I am much disposed to agree with him, that the prospect of suceess by transfusion, and $\mathbf{I}$ may add, by injection, is good in cases of cholera.

London, July, 18d9.

\section{ON THE SUCCESSFUL TREATMENT OF ASTATIC CHOLERA BY SMALL AND FREQUENTLY REPEATED DOSES OF CALOMEL.}

\section{BY JOSEPH AYRE, M.D., Hull.}

MEMBER OF THE ROYAI COLLEGE OF PHYSICIANS, LONDON, AND FORMERLY PIYSICIAN TO THE WULL OENERAL INYIRMARY.

BEFORE I had read, in ThE LANCET of last week, the remarks on my plan of treating the Asiatic cholera, and the invitation to me to communicate the results of my treatment in the present epidemic, $I$ had become aware of many circumstances which should ind nce me to come once more before the public on the subject; for, notwithstanding my having occupied more than twenty of your columns in explaining and recommending the treatment, I had still to lament-judging by the great and continued mortality of the disease-that-my plan of - treating it was only followed very partially, and in numerous cases so imperfectly as to render it wholly unavailing: indeed, acconnts had reached me of parties losing their patients under a treatment which they believed to be mine, and which, in one case, consisted in giving one grain of calomel every hour; and in another, half a grain every half-hour, -as was done also at Tooting, and stated to be my treatment. And I had also learnt that gentlemen had adopted my treatment in individual cases, and after using it for a few hours, had abandoned it, or united other means with it, by which its efficacy was prevented. Being desirous, therefore, of bringing the subject once more before the public, and feeling it to be also a duty imperatively laid upon me, I received with unfeigned satisfaction your- request that I would repert the results of my treatment in the epidemic now raging in this town. This report $I$ now proceed to lay before your readers, and if it shall lead to a general adoption of the treatment, the hope in me will not be vain that it will lead to the saving of thousands of lives.

First, I would remaik, that, agreeably to what you state, I was invited to accept the appointment of physician to the sanitary committee of the board of guardians of this town and at the same time my three friends, Messrs. Day, H. Gibson, and Archbald, were associated with me. Our duty was to take charge of all the cases of Asiatic cholera among the poor of this large town, with above 50,000 inhabitants.

To these gentlemen, in having whom ohosen as my colleagues I esteem myself fortunate, I explained the views I entertained of the nature of the disease, and the treatment $I$ would advise for it. To facilitate the means by which I might have a knowledge of each case as it occurred, a parish officer was appointed to call at the houses of those gentlemen every three hours throughout the day, and to bring to me the name and address of every fresh patient; and none passed through the disease without being seen early by me, and each was visited from time to time by us-all. It is new little more than twenty-three days since the disease reappeared here, and during that period we-have had eighty-one cases of the disease, more or less advanced into the collapsed or blue stage, of the patients in which only ten have died. And here I feel required, in reference to the statement now given of the few deaths that occurred among our patients, to anticipate the inquiry that may be made by your readers, first, as to the degree of severity of the disease; and secondly, as to the circumstances which occasioned seven of the whole to die; for reflection and experience have alike taught me, in regard to this disorder, that the same treatment which is equal to curing twenty patients should be equally efficient in curing thirty, unless some acknowledged causes foreign to the treatment have interfered to prevent it.

1st. As to the intensity of the disorder, it might suffice to take, in their order, the first four cases we were officially called to attend, which, in company with $\mathrm{Mr}$. Archbald and my other colleagues, I especially attended, and by which I aimed at, and succeeded in, the fixing their attention to the mode I followed in the treatment. I gained, by the results of these cases, the entire confidence of $m y$ colleagues in its power. The first case was in a girl, (Marshall,) nineteen years of age, who resided in St. George's-place, Little Passage-street, and had nursed a sister in the same court, who had died under the opiate and stimulant treatment. This patient (the girl) became pulseless, and the discharges were so copious as to pass through the bed, and flow in a stream along the floor. The secretion of the kidneys was stopped for seventy-four hours, being longer by two hours than had happened to any patient I saw in 1832. This patient took* grains of calomel, in two-grain doses, was convalescent, that is to say, was safe from the disease, and free from consecutive fever, and was quite well in eight days. The next patient was also a girl in the same court, (Brewer.) She was thrust out from her lodging in an adjoining house, and, in the absence of its owner, crawled into the house, and got into the bed of a woman who had died of the complaint two days before. She was nearly pulseless, but, like the first patient, was carefully attended by a hired nurse, and was convalescent in two days. The urine was suppressed forty-eight hours. The third case was a youth, (Collins,) aged eighteen, of Duke-street. He had lost his mother a few days before, under the stimulant and opiate treatment, and his sister was dying at the time of our visit, under the same treatment. They had all occupied the same room. The discharges of the patient ran from him, through the bed, and the secretion of the kidneys was suspended sixtythree hours. He took a large quantity of calomel; had very slight ptyalism; was convalescent in three days; and was walking about, in seeming, good health, at the end of the week of his attack. "This patient was seen in eompany with Dr. Sutherland. The fourth patient was a married sister of the foregoing, (Smith.) She had been -several days acting as a nurse to her family, when she was struck down with the disease. She was, however, seen early, and was convalescent in two days, with a slight degree of ptyalism.

But to attain to a just knowledge of the intensity of the disease, the interests of truth demand of me to say, that without any means of knowing the number that have been attaeked, the mortality from the disease in this town has been very great under, the opiate and stimulant-treatment, which has been too generally pursued, and, as I. will presume, from an ignorance of any better method. As the official attendants of the poor, and having been widely advertised as such, my colleagues and myself have necessarily had the greater number of the patients attacked; and when I notice among our recoveries a woman eight months enceinte, a half-famished Irish labourer fetched in by the police from the outside of the town in a cold and lived state, a child two rears and a half old several hours pulseless, -it may be readily imagined that we have had our full share of intensely affected patients.

But as I have-stated, if the treatment be available for the cure of twenty severe cases, it should, ceteris paribus, be available for the cure of thirty, and so on; and $I$ have, in a former report of my treatment and its results, deemed it right, not only to explain how I saved some, but why I did not save all. for in the absence of any-disease previously present, and of the causes now to be noticed, every patient, or well-nigh every patient, might be saved. The causes which have appeared to prevent our entire success in curing all our patientsare mainly

* In a mivate letter to us, received with this paper, Dr -Ayre laments that he has "had to write it amidst incessant interruptions," and is unable to see his collearues before posting it. The above blank appears-in the MS., but it will probably be filled up in a subsequent statement eoncerning the cholera ot Hull - ED, L. 
two-onelof these is a most blameable delay on the part of the friends in sending for medical aid. From causes pertaining either to the constitution of the patient, or to the concentrated intensity of the malaria, the disease differs greatly in different individuals in the rapidity of its course, varying in the period of its fatal termination from four or five hours to twelve or twenty-four. In too many cases, especially when the disorder commences in the night, assistance is not sought for by the friends until four or five hours have elapsed, when the patient is already literally moribund, and when the stomach has become insensible to the influence of every medicinal agent, and the lungs and brain have become irrecoverably congested, as shown by symptoms the most intelligible to those familiar with the disease. But what, if possible, is worse even than delay, and more palpably a hindrance to success in the treatment by calomel, is when the opiate and stimulant treatment has been already tried upon the patient, and which, failing to restore the secretions, increases the congestion, and puts in abeyance those vital sensibilities and sympathies which are needed to render the calomel treatment efficient. Of the ten patients who died, three of whom were children, one was in the disease in its severest forms more than six, and the other about five hours; they were pulseless when visited, and had probably been so for some considerable time. Five had been under treatment by others, and had been drugged with opiates and brandy, and with camphor and cayenne pepper; the ninth was subject to fits of insanity, and when he had considerably recovered from his disease, and had been several days out of collapse, he became suddenly ill, (and if his daughter was to be credited, it was from his having swallowed some hard substances;) and the tenth was a drunkard and of a drunken family, and became affected with congestion of the brain, when he had become fully convalescent and had taken some rum. These, then, are the patients whom we lost, and the circumstances $\mathbf{I}$ have enumerated are the causes which occasioned their loss. It may indeed be the case that the disease is of such intensity as to destroy the vital powers at its first assault; but neither in 1832, nor in the present epidemic, which is to the full as severe in its symptoms as it was then, have I ever met with a case in which, with all the diagnostic symptoms of collapse clearly exhibited, and with a reasonable time afforded to begin it, the treatment I have adopted did not avail to subdue it; and it is with the emphasis and solemnity of truth that I now make this statement, appealing, as I confidently can do, to the experience of my three colleagues in the treatment during the whole time in which we have worked together.

With respect to the treatment pursued by us with calomel, I may here repeat, (what $I$ have stated at some length in my work on the disease, ${ }^{*}$ and in an abridged form in the pages of THE

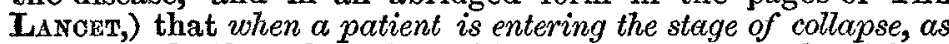
shown by the blue-coloured vomiting and purging, and weight at the procordia and cramps, we begin our treatment by giving a mixed pill, containing two grains of calomel, every ten minutes, with one, or at most two, drops of laudanum in a tea or table spoonful of water; we continue the calomel at the same intervals for five, six, or more hours, watching the course of the symptoms, and taking care to widen the intervals, and reduce the dose of exhibiting the calomel as the coldness and lividness subside; and when the surface has become of a natural temperature, and the pulse natural, it may be wholly discontinued. There is no limit required to be set to the time during which it may be given, or the quantity that may be taken. Pending the duration of the stage of collapse there is no absorption of the calomel into the system, and no benefit to be obtained by aiming at such an effect, and although no evil nor even an inconvenience has been sustained by a slight tenderness of the gums, which is sometimes produced, yet it is not to be desired as a remedial means in this disease. A patient, (Higgins, of Mill-street, ) who was seized on the Sunday, and was walking in the street on the following Saturday quite well, took three hundred and fifty grains of calomel before the collapse was fully removed, and during seventy-seven hours of interrupted urinary secretion, as I have just learnt from Mr. Gibson; and with the exception of a slight tenderness of the gums, and without any flow of saline, she became and still remains in every respect quite well-I have seen her this morning. And this leads me to remark, regarding the results of this mode of treatment, that the operation of the calomel being to restore the secretion of the liver, and thereby remove the congestion of it and of its associated organs, there is no consecutive fever following the collapse and not one of our recovered patients had any degree of fever, but came at once into a state of comparative health in coming * We purpose to give a summary view of the contents of this work in the next, or in a very early, ensuing number of THR $L A N C B T,-$ Sub.Ed, $L$.
. out of their collapse; and although we have had seventy-eight patients in this disease in the space of three weeks, we have never had more than five or six patients under treatinent, the rest having recovered, and if women, have followed their various avocations, one patient being in two or three days sufficiently recovered to be able to act as nurse to another of the family struck down by the disease. The occurrence of ptyalism was so rare and so trifling as to make it of no account, although the average quantity of calomel could not be much less than fifty or sixty grains. In giving laudanum my object has only been to detain the calomel for a time in the stomach, and not with any view to act as a stimulus to rouse and support the vital powers, or as a sedative to remove the cramps; for I have always held and acted upon the opinion, that the abeyance of the vital powers, as shown in the shrunken features and cold and livid surface, and also the cramps, and, indeed, every one of the appalling symptoms of the complaint, are dependent upon a venous congestion of the liver, produced by its interrupted secretion, and that it is by means that will restore that secretion that the whole of its symptoms is to be removed. I care not, therefore, how little laudanum is exhibited, or for how short a time it is continued; and would advise that it should be taken only at wide intervals after forty or fifty drops have been given. I still give it because I originally began $y /$ ith it, and because my patients have recovered under its use; but $I$ am strongly disposed to give the calomel alone, and have already tried it on an infant with suc. cess, although the patient was pulseless when the treatment began.

With respect to any other anxiliary means, my practice is, as it ever was, not to employ any. To our patients not one drop of brandy or other fermented liquor has been given, nor have we ever done more than sometimes to order a hot bottle to be put to the feet, or a small mustard plaster to the stomach, though, I believe, in nine cases out of ten these means have been left unordered. One difficulty we have had to overcome is the negligence of the hireling nurses, and we have often held them to their duty by the promise of a reward if the patient recovered.

And now, Sir, having stated as much as it occurs to me can be needed to make the results of our treatment and the nature and object of it intelligible, I shall conclude by restating what I would desire to be especially insisted on-namely,

1st. That there is no period in the stage of collapse short of a visibly moribund state that should make us despair of restoring the patient, or induce us to desist from using the treatment.

2nd. Whatever may be the quantity of calomel employed during the period of collapse, no evil of any kind results from its use; and when the patient is restored, the only inconvenience that ever happens is a slight tenderness of the gums which may generally be prevented by desisting at the proper time from exhibiting the medicine.

3rd. That opiates in excess, and all stimulants, are to be avoided as especially injurious, and tend to produce in the recovered collapsed patient a state of fever, which may itself become a cause of death, but which never takes place under the calomel treatment, as the patient, in coming out of the collapse, returns to a state of comparative health, and is generally able to walk out of doors in three or four days, and take his food as usual.

4th. That besides the injurious effects justly ascribable to opiates in any considerable quantity, and to all stimulants, whether alcoholic or pharmaceutic, there is a general objection to be offered to all agents, auxiliary or otherwise; when employed to obviate this or that symptom, whether it be the cramps or the coldness, for these are but symptoms of an internal morbid condition, and whatever tends to remove that, removes also all the symptoms dependent on that stage, and my early experience in the efficacy of calomel given in small and frequently repeated doses to remove the morbid cause, has taught me to depend upon that single remedy, unmixed with any other means. As neither in the epidemic of 1832 nor in the present one, have I ever had recourse to any other; so have I never had occasion to regret my exclusive employment of it; and if in the cure of this appalling malady, whose symptoms and course are so unerringly uniform, the calomel in small and constantly repeated doses is not a specific, then is there no remedy that ever merited that name.

I append a tabular view of the cases of diarrhea and cholera which have come tonder our care from the 14 th of July to the 6th instant, with the results; and it will be my care, in your future numbers, to give similar tables. I have divided the cases of cholera into those where the collapse was complete and those in which it was commencing, arrested, and prevented 
from going into collapse. In these cases, our treatment of them varies from two grains every ten minutes, to one grain every ten or twenty minutes, leaving directions that if the disease is not checked, the calomel is to be repeated oftener; we often, however, begin with two grains every ten minutes for three or four times, and then give it at wider intervals. The diarrhcea cases are all treated with a grain of calomel every one or two hours, for three or four times, with or without a few drops of laudanum, or cretaceous mixture.

And now, in bringing this paper to a conclusion, I must remark, that, rejoicing as $I$ do in the large opportunity my appointment has given me of testing once more my treatment; and fortunate as $I$ am in having such able and zealous coadjutors for my colleagues, who witness and rejoice in its success, I cannot forbear expressing $m y$ regret that the municipal authorities of this town, in 1832, refused compliance with my request, that a committee of six persons, three of whom should be medical, might be formed for visiting and reporting upon the state of all my cholera patients, and the results of the treatment. But especially I regret that an application has been declined which I made little more than a week ago, to the Board of Health, with a view to their sending down one or more medical inspectors to visit all our cases, and witness the treatment of them, and report weekly the results. Had this request been granted, I can believe that the question of its power to cure the disease would have been so settled in its fayour, and that a report of it going out first under the authority of government would have ensured its adoption wherever the disease prevailed.

A return made to the sanitary committee of the court of guardians for the poor of the town of Kingston-upon-Hull of the number of cases of diarrhoa and of cholera, incipient and entire, which came under the care of Dr. Ayre, physician, and Messrs. Day, H. Gibson, and Archbald, surgeons, between the 14th of July and the 6 th of August.

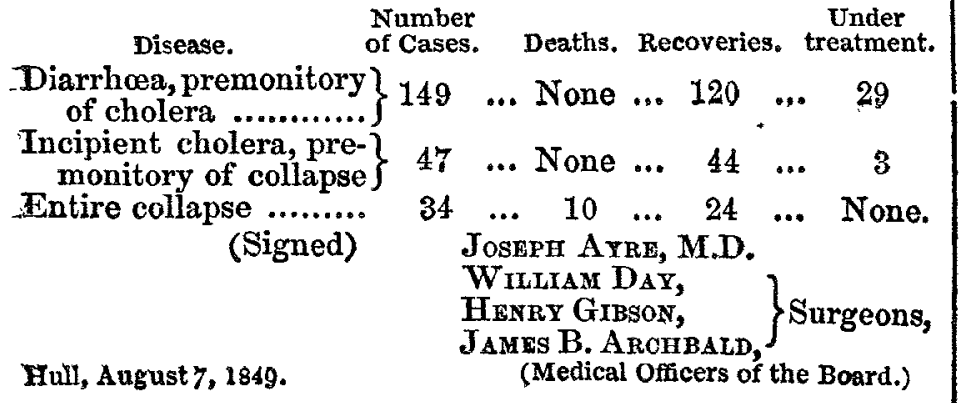

\section{SUCCESSFUL TREATMENT OF MALIGNANT CHOLERA ON THE PLAN OF DR. AYRE.}

BY GEORGE M. PRITCHETT, Esq., M.R.C.S., \&c., London.

As the medical world seems so much divided in opinion respecting the treatment of Asiatic cholera, and fully coinciding in the remarks made in last week's LANCET respecting the efficacy of the treatment adopted by Dr. Ayre of Hull, as evidenced in the diminished mortality in his practice, $I$ think it my duty to send for publication an outline of two well-marked cases successfully treated by his method. Several cases at an earlier stage have come under my notice, which have yielded like a charm to a very few grain doses of calomel and two drops of laudanum in four teaspoonfuls of brandy-andwater every hour only. In a disease of so much intensity, where we have so deadly a foe to grapple with, I think practice far better than theory, and it appears to me that we have at command a safe and simple treatment, almost specific, that were it generally adopted, would deprive the disease of nearly all its fell terrors. In Dr. Ayre's paper, published in TrE LAYCET of the 28th of October last, I find in 1832, that out of 219 cases there were 176 recoveries and only 43 deaths; while in this visitation the 59 cases, as appears in last week's LANCET, treated by him from the 14 th to the 26 th ult., were all successful, while nine treated by others all ended fatally. Surely such facts as these speak for themselves, and need no comment.

CASE 1.-D. A - a young barrister, aged twenty-five, who had been reading hard for some time, and also weakened considerably by previous indisposition, sent for me at three P.M. May 2nd. I found him before the fire on the sofa, complaining of much pain in the bowels, with a shrunken countenance of a dusky colour; frequent vomiting with diarrhoea, intermitting pulse, and slight cramps in the extremities. Thinking the attack would pass off by ordinary remedies, I prescribed a calomel-and-opium pill, and some simple effervescing draughts, with a few drops of laudanum in each dose, also brandy-andwater, \&c. At nine P.M. I was again called, when all the symptoms were much aggravated; diarrhca very frequent, stools, as well as could be ascertained, of the rice-water character; vomiting constant; rejection of all food and medicine as soon as taken; cramps violent all over the body and extremities; pulse very feeble and intermitting; the skin quite cold and livid; and the face had assumed that ghastly appearance so well known in this disease. No urine had passed since the commencement of the attack; and extreme collapse was rapidly supervening. The treatment adopted was simply a one-grain calomel pill every quarter of an hour, with two drops of laudanum in four teaspoonfuls only of brandy-and-water together with bottles of hot water applied to the extremities, and a mustard cataplasm to the pit of the stomach; in one hour the diarrhcea and vomiting ceased; in four, reaction had commenced, and the cramps were much lessened; twelve doses only were given in all. The after treatment was a little troublesome from the previously weakened state of the patient, but under simple remedies he rapidly progressed, and no prominent symptom need be enumerated.

CASE 2.-Mrs. S-, aged forty, living over stables in Chenies-mews, sent for me on the 11th of July, at seven A.M. I found she had had diarrhoea for some days previously, and had for some hours been getting gradually worse; in fact, all the symptoms of cholera were present, constant vomiting and purging, with well marked rice-water evacuations, quite unmixed with any freculent matter; urine suppressed; violent cramps; livid countenance; shrunk features; pulse scarcely to be felt; coldness of the surface, and collapse commencing. The treatment adopted was precisely the same as in Case 1 , with the same results. In one hour the vomiting and purging ceased; and in four the skin was getting warm; the calomel was continued at intervals of two and three hours during the day, the cramps not ceasing entirely.

July 12th.-Patient much better, only weak from the effects of the attack, with slight ptyalism of no importance. The patient progressed favourably under simple treatment, and in a fệ days was quite wẹll,

Store-street, Bedford-square, A ugtist, 18 490 .

\section{Betporir of A}

CASE OF ABSCESS OF THE SPERMA TIIC CORD.

\section{BY WILLIAM PHILPOT BROOKES, M.D., \&c.,}

SUROEON TO THE CHELTENHAM GENERAL HOSPITAL AND DISPENSARY, AND VISITING MEDICAL OPFICER TO THE CXELTENHAM COUNTY DIVISION OF LUNATIC ASYLUAS, \&c.

R. W-, aged fifty-one years, of active, spare habit of body, irritable and very anxious disposition, living as butler in the family of a gentleman in Cheltenham, enjoyed uninterrupted good health till within the last few months.

Six months back, after much pain and suffering, he passed a large-sized gravel-stone; after that time his usual good health was restored.

On Wednesday, June 28, 1848, I was requested to attend him. I found the patient suffering from fever, constipation, pain on pressure in the abdominal region, and extensive pain around the margin of the ribs of the right side. On examination of the groin I learnt that he had suffered for several years from a double inguinal hernia, and had constantly worn a truss of Salmon and Ody's construction. There was, on the right side, above Poupart's ligament, a round, cup-shaped depression, as large and deep as a small saucer, caused by the pad of the truss slipping out of its proper situation; and extensive pressure having been kept up with the pad, which was hard and convex on this spot, he complained of excruciating pain, and could barely allow it to be touched. The heat of the part was far above the natural temperature, and the skin was of a reddish-brown hue; the pulse was very quick and sharp; bowels had not acted for two days; tongue foul; hernia easily reduced. I ordered him five grains of calomel to be taken directly; a black draught in the morning; and a dozen leeches, with warm fomentations and poultices, to be applied to the abdomen afterwards. An enema to be given at bed-time if he had had no evacuation before that time.

June 29th.-Bowels not opened; the enema passed away without any frecal matter. Great pain over the whole abdomen and around the edges of the liver; tongue white and foul; pulse quick and wiry; urine scanty and high-coloured. To take two grains of calomel, and half a grain of opium, every four hours. An enema to be given directly; twelve leeches to be again applied over the bowels, and afterwards warm poultices to be kept constantly applied. 